\title{
A novel and Rapid LC-MS/MS assay for the Determination of Mycophenolate and Mycophenolic Acid in Human Plasma
}

\author{
Rambabu Maddela ${ }^{1,2}$, Nageswara Rao Pilli ${ }^{1,2}$, Srinubabu Maddela ${ }^{1}$, Chalapathi Rao Pulipati ${ }^{2}$, Srinivasa Rao Polagani ${ }^{2}$, Ajitha Makula ${ }^{1 *}$ \\ 'Department of Pharmaceutical Analysis, Center for Pharmaceutical Sciences, Jawaharlal Nehru Technological University Hyderabad, Kukatpally, Hyderabad-500 085, \\ INDIA. \\ ${ }^{2}$ Department of Bioanalysis, PCR Laboratories, Ramanthapur, Hyderabad-500 013, INDIA.
}

\begin{abstract}
Objective: The main goal of this research was to develop a simple, rapid and sensitive liquid chromatography/tandem mass spectrometry (LC-MS/ MS) method for the simultaneous quantification of mycophenolate mofetil and mycophenolic acid. Methods: Sample extraction was carried out using a simple solid phase extraction (SPE) technique. The extracted samples were chromatographed on a $\mathrm{C}_{18}$ column using an isocratic mobile phase composed of acetonitrile and $0.1 \%$ formic acid buffer $(80: 20$, v/v) pumped at a flow rate of $1.00 \mathrm{~mL} / \mathrm{min}$. Results: Method linearity was established in the concentration range of $0.10-20.0 \mathrm{ng} / \mathrm{mL}$ for mycophenolate mofetil and 101-19955 ng/mL for mycophenolic acid. Intra-day and inter-day precision and accuracy results of mycophenolate mofetil and mycophenolic acid were well within the acceptance criteria specified in the US FDA and EMEA guidelines. Conclusion: The projected LC-MS/MS assay method is simple, rapid and sensitive for the simultaneous determination of mycophenolate mofetil and mycophenolic acid in human plasma. This method
\end{abstract}

was successfully used to quantitate the in-vivo plasma concentrations obtained from a pharmacokinetic study.

Key words: Mycophenolate mofetil, Mycophenolic acid, Human plasma, Liquid chromatography-tandem mass spectrometry (LC-MS/MS), Method validation, Pharmacokinetics.

Correspondence :

Ajitha Makula,

Department of Pharmaceutical Analysis,

Center for Pharmaceutical Sciences,

Jawaharlal Nehru Technological University Hyderabad,

Kukatpally, Hyderabad-500 085, INDIA.

E-mail: rambabu1974@gmail.com (R. Maddela); ajitharaj@hotmail.com (A. Makula) DOI: 10.5530/jyp.2017.9.20

\section{INTRODUCTION}

Mycophenolic acid (MPA) is an immunosuppressant drug used to prevent the rejection of organ transplantation and also in the treatment of autoimmune disease. ${ }^{1}$ To improve its oral bioavailability, MPA is administered as mycophenolate mofetil (MP). ${ }^{2}$ An oral dose of MP is hydrolyzed rapidly during first-pass metabolism to mycophenolic acid (MPA) which is further metabolized to two minor metabolites namely acyl glucuronide (AcMPAG) and phenolic glucoside of MPA. MPA is highly bound to plasma proteins, mainly to human serum albumin (97-99\%). ${ }^{3} \mathrm{MP}$ is available for oral administration as capsules containing $250 \mathrm{mg}$ and $500 \mathrm{mg}$.

Literature survey reveals, many HPLC ${ }^{4-6}$ and LC-MS/MS ${ }^{7-15}$ based methods have been reported for the determination of MPA in biological samples. Similarly, very few HPLC methods have been reported for the determination of MP alone ${ }^{16}$ and in combination with MPA. ${ }^{17}$ Now a days, conventional HPLC methods are not utilizing by the bioanalytical scientists due to limitations in its rapidity, resolution and sensitivity. Hence there is a need for fast or ultra-fast methods such as LC-MS/MS without compromising on the sensitivity and efficiency. LC-MS methods are widely adopted in bioanalytical applications due to its specificity and high sensitivity. ${ }^{18}$ For a bioavailability and bioequivalence studies, it is necessary to quantify the MP and MPA concentrations in in-vivo samples. ${ }^{19}$ Till date, no LC-MS/MS method has been reported for the determination of MP individually or simultaneously with MPA in any of the biological matrices.

With the above, the authors made an attempt to develop a specific, sensitive and rapid LC-MS/MS method for simultaneous determination of $\mathrm{MP}$ and MPA in $50 \mu \mathrm{L}$ of human plasma using mycophenolate mofetil d4
(IS1) and mycophenolic acid d3 (IS2) as internal standards, respectively. The method found to be significantly free from the possible interferences and was successfully applied to a pharmacokinetic study in South Indian healthy male subjects.

\section{MATERIALS AND METHODS}

Reference standards and solvents

Mycophenolate mofetil (98.80\%) reference standard was obtained from the Hetero Labs Limited, India, whereas mycophenolic acid (98.03), mycophenolate mofetil-d4 hydrochloride (98.72\%) and mycophenolic acid d3 (98.00) were purchased from Clearsynth Labs Pvt. Limited, India. LC-MS grade water was prepared at our laboratory. Blank plasma lots from ten individual sources were procured from Deccan's Pathological Labs, (Hyderabad, India). HPLC grade methanol and acetonitrile were purchased from J.T Baker (Phillipsburg, USA). Analytical grade formic acid and ammonium acetate were obtained were purchased from Merck Limited, (Mumbai, India).

\section{LC-MS/MS instrument and conditions}

An API-4000 (AB Sciex, Applied Biosystems, Foster City, CA, USA) mass spectrometer coupled with HPLC system (Shimadzu Corporations, Kyoto, Japan) was used for the study. A mixture of acetonitrile and 0.1\% formic acid (80:20, v/v) was used as mobile phase and delivered at a flow rate of $1.0 \mathrm{~mL} / \mathrm{min}$. An aliquot of $20 \mu \mathrm{L}$ of processed samples were injected in to Kromasil 100-5 $\mathrm{C}_{18}, 100^{\star} 4.6 \mathrm{~mm}, 5 \mu \mathrm{m}$ (Make: Akzonobel) analytical column which was kept at ambient temperature $\left(20 \pm 5^{\circ} \mathrm{C}\right)$. The optimized parameters are listed in Table 1. 


\section{Preparation of stock and working solutions}

Stock solutions of analytes and the internal standards were prepared in HPLC grade methanol. Two separate stock solutions of analytes at a concentration of $1 \mathrm{mg} / \mathrm{mL}$ were prepared for the preparation of calibration curve standards and quality control samples. Further working solutions of analytes were prepared in a mixture of water and methanol (50:50, v/v; diluent). A combined working solution for IS1 (100 ng/mL) and IS2 $(4000 \mathrm{ng} / \mathrm{mL})$ was also prepared in diluent. All the stock solutions were store at $2-8^{\circ} \mathrm{C}$ in refrigerator and they were found to be stable for 23 days.

\section{Calibration curve standards and quality control samples}

Calibration standards and quality control samples were prepared by spiking a $50 \mu \mathrm{L}$ aliquot of combined working standard solution of the analytes in to $950 \mu \mathrm{L}$ of screened human blank plasma. Nine calibration standards were prepared at a concentration of $0.10,0.20,0.50,1.20,3.00$, 6.00, 12.0, 16.4 and $20.0 \mathrm{ng} / \mathrm{mL}$ for MP and 101, 201, 503, 1198, 2994, 5989, 11978, 16363 and $19955 \mathrm{ng} / \mathrm{mL}$ for MPA. Quality control samples were prepared at five concentration levels namely LLOQ QC, LQC, MQC1, MQC2 and HQC (See nominal concentrations in Table 2). All the plasma samples were stored at $-70 \pm 10^{\circ} \mathrm{C}$.

\section{Extraction of plasma samples}

The icy samples were thawed at room temperature and vortexed to mix the contents. A $50 \mu \mathrm{L}$ aliquot of plasma sample was pipetted into prelabelled polypropylene tubes and spiked with $20 \mu \mathrm{L}$ of internal standard dilution (100 $\mathrm{ng} / \mathrm{mL}$ of IS and $4000 \mathrm{ng} / \mathrm{mL}$ of IS2). Then the entire sample was vortexed for $10 \mathrm{~s}$. To this, $50 \mu \mathrm{L}$ of $100 \mathrm{mM}$ ammonium acetate buffer was added and vortex.

Strata-X $33 \mu \mathrm{m}$ polymeric sorbent SPE cartridges $(30 \mathrm{mg} / 1 \mathrm{~mL})$ were place onto SPE positive pressure processing unit (Ezypress 48 ). All the cartridges were conditioned with $1.0 \mathrm{~mL}$ of methanol and equilibrated with $1.0 \mathrm{~mL}$ of water and $1.0 \mathrm{~mL}$ of $100 \mathrm{mM}$ ammonium acetate buffer. Then the entire sample mixture was loaded onto a cartridge and slowly eluted with the gentle stream of nitrogen. After applying the maximum pressure, the cartridge was washed with $1.0 \mathrm{~mL} 100 \mathrm{mM}$ ammonium acetate buffer followed by $2 \mathrm{~mL}$ of water ( $1.0 \mathrm{~mL}$ of each time). Analytes and the internal standards were eluted with $0.5 \mathrm{~mL}$ of mobile phase and loaded into auto-sampler.

\section{Method validation}

Method validation was carried out as per US FDA ${ }^{20}$ and EMEA guidelines. ${ }^{21}$ The validation parameters tested are system suitability, carryover test, selectivity, specificity, sensitivity, matrix effect, linearity, precision and accuracy, recovery, dilution integrity, stability and run size evaluation.

\section{RESULTS AND DISCUSSION}

\section{Method development}

The objective of the present work is to develop a simple and rapid LC-MS/MS method for the simultaneous determination of MP and MPA suitable for bioavailability and bioequivalence studies. LC-MS/MS conditions were optimized by infusion of the neat solution with the diluent. MP and MPA exhibited favorable sensitivity in positive ion mode detection because of the efficiency of ionization of the analyte. The product ion mass spectrum of MP, MPA, IS1 and IS2 from $[\mathrm{M}+\mathrm{H}]^{+}$precursor ion to product ion is shown in Figure 1a, 1b, 1c and 1d, respectively. The intense product ion of m/z: 114.1 was selected for MP, m/z: 207.2 for MPA, m/z: 118.2 for IS1 and m/z: 210.2 for IS2. The MRM state file parameters such as DP, $\mathrm{CE}, \mathrm{CXP}, \mathrm{GS} 1, \mathrm{GS} 2, \mathrm{CAD}$ gas, ion spray voltage and temperature were suitably altered to get intense and reproducible response. The present study was conducted using ESI ionization source as it produced high intensity and a good linearity for the analytes. Multiple reaction monitoring (MRM) provides inherent selectivity and sensitivity for pharmacokinetic studies, hence was chosen for the present assay development. The dwell time for each transition was set at $200 \mathrm{~ms}$, no cross talk was found between the MRM channels of analytes and internal standards.

Chromatographic separation was performed in isocratic mode. The separation of analytes and the internal standards could be achieved by changing the composition of methanol and acetonitrile in the mobile phase. The use of volatile buffer namely ammonium acetate and ammonium formate and acidic buffer like formic acid and acetic acid for the separation of analytes had been evaluated also. An isocratic mobile phase composed of acetonitrile and $0.1 \%$ formic acid $(80: 20, \mathrm{v} / \mathrm{v})$ as gave symmetric peak shape, better separation and best sensitivity for the analytes. Among the various chromatographic columns tested for their suitability Kromasil $\mathrm{C}_{18}, 100 \times 4.6 \mathrm{~mm}, 5 \mu \mathrm{m}$ column gave good peak shape and response even at lowest concentration level for both the analytes. The mobile phase flow rate was set at $1.0 \mathrm{~mL} / \mathrm{min}$ allowing a run time of $2.5 \mathrm{~min}$. The retention time of MP, MPA, IS1 and IS2 were found to be $0.9,1.3,0.9$ and $1.3 \mathrm{~min}$.

Initially, liquid-liquid extraction (LLE) was evaluated to extract the drugs from plasma using ethyl acetate, hexane, dichloromethane and tert-butyl methyl ether alone or in combination as extraction solvents. But the recovery of the analytes were inconsistent at lower concentration level due to matrix effect. As a purpose to develop an efficient extraction procedure with minimal or no matrix effect, SPE was tried using a variety of cartridges like Oasis HLB, Orpheus C18 extraction, Starata polymeric sorbent and Bond Elut Plexa. Of all the above, promising results were achieved with Strata-X $33 \mu \mathrm{m}$ polymeric sorbent cartridge $(30 \mathrm{mg} / \mathrm{mL}$ ) gave superior recovery for the analytes compared with LLE and the influence on sensitivity is significantly less. Addition of ammonium acetate as an extraction additive helped in achieving the high recoveries for the analytes. Also, using ammonium acetate during washing step imparted consistent recovery with minimal or no matrix interference. Initially, samples were eluted with methanol and injected. But the results were not reproducible due to bad peak shape. Hence, analytes were eluted with the mobile phase and injected.

An ideal internal standard should preferably be belong to the same class, with the similar physicochemical and spectral properties. Use of isotope-labeled drugs as internal standards are suggested to improve the method precision, accuracy and linearity. ${ }^{22}$ Hence, mycophenolate mofetil $\mathrm{d} 4$ and mycophenolic acid $\mathrm{d} 3$, an isotopic labeled compounds of mycophenolate mofetil and mycophenolic acid, were selected as an internal standards, respectively for the current study and were found to be best for the present purpose.

\section{System suitability and carryover test}

LC-MS system performance was evaluated through system suitability test. Six consecutive injections of a neat sample containing analytes and internal standards were injected in to the LC-MS system every day before start of the analysis. The precision (\% CV) for system suitability test was found to be less than $1 \%$ for retention time and $2.0 \%$ for area ratio of MP and MPA. No significant carryover effect was observed in subsequent blank sample after injection of ULOQ samples.

\section{Chromatography, signal-to-noise $(\mathrm{S} / \mathrm{N})$ ratio and sensitivity}

Representative chromatograms obtained from analysis blank plasma, plasma spiked with LLOQ, and real subject sample ( $2 \mathrm{~h}$ ) for MP and MPA are presented in Figure $2 \& 3$, respectively. No significant interference was detected at mass transition of MP and MPA in 10 different lots of human plasma including lipemic and hemolyzed plasma. Similarly, 
Table 1: Tandem mass-spectrometer main working parameters

\begin{tabular}{|c|c|c|c|c|}
\hline \multirow{2}{*}{ Parameter } & \multicolumn{4}{|c|}{ Analyte } \\
\hline & MP & IS1 & MPA & IS2 \\
\hline Mode of analysis & Positive & Positive & Positive & Positive \\
\hline Ion transition, $\mathrm{m} / \mathrm{z}$ & $434.3 / 114.1$ & $438.2 / 118.2$ & $338.2 / 207.2$ & $341.2 / 210.2$ \\
\hline Source temperature, ${ }^{\circ} \mathrm{C}$ & 500 & 500 & 500 & 500 \\
\hline Dwell time per transition, msec & 200 & 200 & 200 & 200 \\
\hline Nebulizer gas (GS1), psi & 40 & 40 & 40 & 40 \\
\hline Turbolon gas (GS2), psi & 30 & 30 & 30 & 30 \\
\hline Curtain gas, psi & 20 & 20 & 20 & 20 \\
\hline Collision gas, psi & 8 & 8 & 8 & 8 \\
\hline Ion spray voltage, $\mathrm{V}$ & 5500 & 5500 & 5500 & 5500 \\
\hline Entrance potential, $\mathrm{V}$ & 10 & 10 & 10 & 10 \\
\hline Declustering potential, $\mathrm{V}$ & 80 & 80 & 35 & 35 \\
\hline Collision energy, V & 38 & 38 & 60 & 60 \\
\hline Collision cell exit potential, $\mathrm{V}$ & 10 & 10 & 10 & 10 \\
\hline Resolution & Unit & Unit & Unit & Unit \\
\hline
\end{tabular}

Table 2: Precision and accuracy data for MP and MPA

\begin{tabular}{|c|c|c|c|c|c|c|c|}
\hline \multicolumn{2}{|r|}{ QC } & \multicolumn{3}{|c|}{$\begin{array}{l}\text { Intra-day precision and accuracy ( } n=12 ; 6 \text { from each } \\
\text { batch) }\end{array}$} & \multicolumn{3}{|c|}{$\begin{array}{l}\text { Inter-day precision and accuracy ( } n=30 ; 6 \text { from each } \\
\text { batch) }\end{array}$} \\
\hline Analytes & $\begin{array}{l}\text { Concentration } \\
\text { spiked }(\mathrm{ng} / \mathrm{mL})\end{array}$ & $\begin{array}{l}\text { Concentration found } \\
\text { (mean; } \mathrm{ng} / \mathrm{mL} \text { ) }\end{array}$ & Precision (\%) & Accuracy (\%) & $\begin{array}{l}\text { Concentration found } \\
\text { (mean; } \mathrm{ng} / \mathrm{mL} \text { ) }\end{array}$ & Precision (\%) & Accuracy (\%) \\
\hline \multirow{4}{*}{ MP } & 0.10 & $0.10 \pm 0.005$ & 4.85 & 97.2 & $0.10 \pm 0.005$ & 4.70 & 96.4 \\
\hline & 0.30 & $0.30 \pm 0.011$ & 3.64 & 101 & $0.30 \pm 0.020$ & 6.69 & 99.7 \\
\hline & 2.07 & $2.15 \pm 0.062$ & 2.89 & 104 & $2.13 \pm 0.105$ & 4.95 & 103 \\
\hline & 16.7 & $17.9 \pm 0.388$ & 2.16 & 107 & $17.4 \pm 0.992$ & 5.70 & 104 \\
\hline \multirow{4}{*}{ MPA } & 104 & $101 \pm 2.46$ & 2.44 & 96.7 & $100 \pm 2.21$ & 2.20 & 96.2 \\
\hline & 302 & $280 \pm 7.16$ & 2.56 & 92.5 & $296 \pm 26.6$ & 9.00 & 97.8 \\
\hline & 2100 & $2127 \pm 37.6$ & 1.77 & 101 & $2118 \pm 82.2$ & 3.88 & 101 \\
\hline & 10500 & $9777 \pm 98.0$ & 1.00 & 93.1 & $9779 \pm 545$ & 5.57 & 93.1 \\
\hline
\end{tabular}

over-the-counter (OTC) drug effect on the selectivity of the proposed was also evaluated with acetaminophen, diphenhydramine, pantoprazole, nicotine, ibuprofen, caffeine and pseudoephedrine. Results reveals that no effects of cross-talk were observed. The $\mathrm{S} / \mathrm{N}$ ratio observed during method validation and study sample analysis was $>5$ for both MP and MPA.

Sensitivity was determined at a concentration of 0.10 and $101 \mathrm{ng} / \mathrm{mL}$ for MP and MPA, which was set a lowest limit of reliable quantification (LLOQ). Six replicates of LLOQ samples were prepared from the screened blank samples and analyzed samples were quantified using a calibration curve. At this concentration, the precision and accuracy results of MP were found to be $8.53 \%$ and $111 \%$. Similarly, the precision and accuracy results of MPA were found to $2.90 \%$ and $101 \%$.

\section{Matrix effect}

Matrix effect assessment is important for LC-MS/MS, where significant matrix effect is possible. The average matrix factor valve calculate as the response of the post spiked sample/response of neat sample at LQC and HQC level was 1.03 and 1.01 for MP and 0.99 and 0.98 for MPA, respectively, which indicated negligible suppression or enhancement.

Also, relative matrix effect was calculated at LQC and HQC concentration for both the analytes. Three replicates of LQC and HQC samples were prepared from the each screened blank samples obtained from 10 individual sources and analyzed. The precision and accuracy for MP at LQC concentration were found to be $2.35 \%$ and $98.9 \%$, and at HQC level they were $0.70 \%$ and $104 \%$, respectively. Similarly, the precision and accuracy for MPA at LQC concentration were found to be $3.33 \%$ and $90.2 \%$, and at HQC level they were $1.54 \%$ and $91.6 \%$, respectively. 
Table 3: Stability samples result for MP and MPA $(n=6)$

\begin{tabular}{|c|c|c|c|c|c|}
\hline Analyte & Stability test & $\begin{array}{c}\text { QC (spiked } \\
\text { concentration }(\mathrm{ng} / \mathrm{mL})\end{array}$ & Mean \pm SD $(\mathrm{ng} / \mathrm{mL})$ & $\begin{array}{c}\text { Precision } \\
\text { (\%) }\end{array}$ & $\begin{array}{l}\text { Accuracy/ } \\
\text { Stability (\%) }\end{array}$ \\
\hline \multirow[t]{12}{*}{ MP } & Process $^{\mathrm{a}}$ & 0.30 & $0.30 \pm 0.01$ & 3.33 & 99.3 \\
\hline & & 16.7 & $18.0 \pm 0.42$ & 2.33 & 108 \\
\hline & Process $^{\mathrm{b}}$ & 0.30 & $0.28 \pm 0.01$ & 2.07 & 95.4 \\
\hline & & 16.7 & $17.8 \pm 0.26$ & 1.46 & 107 \\
\hline & Bench top ${ }^{c}$ & 0.30 & $0.31 \pm 0.01$ & 3.53 & 103 \\
\hline & & 16.7 & $18.5 \pm 0.71$ & 3.84 & 111 \\
\hline & $\mathrm{FT}^{\mathrm{d}}$ & 0.30 & $0.30 \pm 0.01$ & 3.29 & 99.6 \\
\hline & & 16.7 & $17.4 \pm 0.24$ & 1.38 & 104 \\
\hline & Reinjection ${ }^{\mathrm{e}}$ & 0.30 & $0.28 \pm 0.01$ & 3.62 & 94.1 \\
\hline & & 16.7 & $18.4 \pm 0.64$ & 3.46 & 110 \\
\hline & Long-term ${ }^{f}$ & 0.30 & $0.28 \pm 0.01$ & 3.98 & 95.7 \\
\hline & & 16.7 & $18.4 \pm 0.07$ & 0.40 & 111 \\
\hline \multirow[t]{12}{*}{ MPA } & Process $^{\mathrm{a}}$ & 302 & $279 \pm 14.2$ & 5.10 & 92.1 \\
\hline & & 16936 & $16028 \pm 337$ & 2.10 & 94.6 \\
\hline & Process $^{\mathrm{b}}$ & 302 & $274 \pm 3.54$ & 1.30 & 90.5 \\
\hline & & 16936 & $15273 \pm 1023$ & 6.70 & 90.2 \\
\hline & Bench top ${ }^{c}$ & 302 & $295 \pm 14.2$ & 4.83 & 97.5 \\
\hline & & 16936 & $16431 \pm 347$ & 2.11 & 97.0 \\
\hline & $\mathrm{FT}^{\mathrm{H}}$ & 302 & $283 \pm 6.69$ & 2.37 & 93.4 \\
\hline & & 16936 & $15503 \pm 461$ & 2.97 & 91.5 \\
\hline & Reinjection ${ }^{e}$ & 302 & $286 \pm 12.6$ & 4.39 & 95.9 \\
\hline & & 16936 & $15577 \pm 324$ & 2.08 & 93.2 \\
\hline & Long-term ${ }^{f}$ & 302 & $288 \pm 7.35$ & 2.55 & 95.4 \\
\hline & & 16936 & $16204 \pm 474$ & 2.93 & 95.7 \\
\hline
\end{tabular}

a after $54 \mathrm{~h}$ in autosampler at $10^{\circ} \mathrm{C} ;{ }^{\text {b }}$ after $51 \mathrm{~h}$ in refrigerator at $2-8^{\circ} \mathrm{C} ;{ }^{\mathrm{c}}$ after $9 \mathrm{~h}$ at room temperature; ${ }^{\mathrm{d}}$ after 4 freeze and thaw cycles; ${ }^{\mathrm{e}}$ after $37 \mathrm{~h}$ of Reinjection; ${ }^{\mathrm{f}}$ at $-70^{\circ} \mathrm{C}$ for 80 days

Table 4: Whole blood stability data for MP and MPA ( $n=6)$

\begin{tabular}{ccccc}
\hline Analyte & Spiked concentration $(\mathrm{ng} / \mathrm{mL})$ & $\begin{array}{c}\text { Mean peak area ratio of } \\
\text { stability sample } \pm \text { SD }\end{array}$ & $\begin{array}{c}\text { Mean peak area ratio of } \\
\text { comparison sample } \pm \text { SD }\end{array}$ & Stability (\%)* \\
\hline \multirow{2}{*}{ MP } & 0.30 & $0.03 \pm 0.001$ & $0.03 \pm 0.001$ & 99.5 \\
& 16.7 & $1.91 \pm 0.044$ & $1.85 \pm 0.027$ & 103 \\
MAP & 302 & $0.02 \pm 0.001$ & $0.02 \pm 0.001$ & 95.7 \\
\end{tabular}

${ }^{a}$ Expressed as [mean area ratio of stability samples/mean area ratio of comparison samples] $\times 100$.

Table 5: Pharmacokinetic parameters of MP and MPA ( $n=10$, Mean \pm SD)

\begin{tabular}{ccc}
\hline Parameter & MP & MPA \\
\hline $\mathrm{C}_{\max }(\mathrm{ng} / \mathrm{mL})$ & $14.6 \pm 3.30$ & $10437 \pm 1829$ \\
$\mathrm{t}_{\max }(\mathrm{h})$ & $1.35 \pm 0.29$ & $1.33 \pm 0.29$ \\
$\mathrm{AUC}_{0-\mathrm{t}}(\mathrm{ng} \mathrm{h} / \mathrm{mL})$ & $29.7 \pm 11.9$ & $22690 \pm 7362$ \\
$\mathrm{AUC}_{0-\text { inf }}(\mathrm{ng} \mathrm{h} / \mathrm{mL})$ & $30.9 \pm 12.3$ & $25227 \pm 8299$ \\
$\mathrm{t}_{1 / 2}(\mathrm{~h})$ & $4.14 \pm 3.29$ & $8.27 \pm 4.08$ \\
$\mathrm{Kel}\left(\mathrm{h}^{-1}\right)$ & $0.26 \pm 0.15$ & $0.11 \pm 0.06$ \\
\hline
\end{tabular}

Linearity, precision and accuracy

The linearity of MP and MPA was determined by weighted least square regression analysis of standard plot that consisted of 9 point standard curve. After comparing the two weighting models $\left(1 / \mathrm{x}\right.$ and $\left.1 / \mathrm{x}^{2}\right)$, a regression equation with a weighting factor of $1 / \mathrm{x}^{2}$ of the drug to the IS concentration was found to produce the best fit for the chromatographic response versus concentrations for both the analytes in human plasma. The calibration was linear from 0.10 to $20.0 \mathrm{ng} / \mathrm{mL}$ for MP and 101 to $19955 \mathrm{ng} / \mathrm{mL}$ for MPA. The correlation coefficient was constantly greater 
Table 6: Incurred samples re-analysis data of MP and MPA

\begin{tabular}{|c|c|c|c|c|c|c|c|c|}
\hline \multirow[b]{2}{*}{$\begin{array}{c}\text { Subject } \\
\text { no. }\end{array}$} & \multicolumn{4}{|c|}{ MP } & \multicolumn{4}{|c|}{ MPA } \\
\hline & $\begin{array}{l}\text { Sampling } \\
\text { point (h) }\end{array}$ & $\begin{array}{c}\text { Initial } \\
\text { conc. (ng/ } \\
\mathrm{mL})\end{array}$ & $\begin{array}{c}\text { Re-assay } \\
\text { conc. (ng/ } \\
\mathrm{mL})\end{array}$ & $\begin{array}{c}\text { Difference } \\
{ }^{a}(\%)\end{array}$ & $\begin{array}{c}\text { Sampling } \\
\text { point (h) }\end{array}$ & $\begin{array}{c}\text { Initial } \\
\text { conc. (ng/ } \\
\mathrm{mL})\end{array}$ & $\begin{array}{c}\text { Re-assay } \\
\text { conc. (ng/ } \\
\mathrm{mL})\end{array}$ & $\begin{array}{c}\text { Difference } \\
\text { a (\%) }\end{array}$ \\
\hline 1 & 1 & 12.9 & 12.1 & 5.96 & 2 & 6738 & 6898 & -2.36 \\
\hline 1 & 9 & 0.32 & 0.34 & -6.13 & 9 & 366 & 342 & 6.72 \\
\hline 2 & 1.5 & 13.6 & 13.3 & 2.12 & 1.5 & 7792 & 7700 & 1.19 \\
\hline 2 & 7 & 0.40 & 0.35 & 14.0 & 9 & 305 & 300 & 1.68 \\
\hline 3 & 0.83 & 7.94 & 7.83 & 1.40 & 0.5 & 8690 & 8989 & -3.39 \\
\hline 3 & 7 & 0.36 & 0.41 & -13.9 & 3.5 & 309 & 312 & -0.83 \\
\hline 4 & 1 & 9.25 & 8.93 & 3.50 & 1 & 8944 & 8821 & 1.38 \\
\hline 4 & 4 & 0.40 & 0.39 & 1.53 & 8 & 380 & 400 & -5.12 \\
\hline 5 & 1.25 & 11.9 & 11.0 & 8.28 & 1.75 & 7562 & 7401 & 2.15 \\
\hline 5 & 12 & 0.38 & 0.38 & 0.26 & 5 & 302 & 289 & 4.30 \\
\hline 6 & 1.5 & 12.1 & 13.3 & -9.54 & 1.5 & 8638 & 8755 & -1.34 \\
\hline 6 & 10 & 0.30 & 0.30 & 3.01 & 20 & 344 & 341 & 0.96 \\
\hline 7 & 2 & 11.7 & 11.7 & 0.01 & 1.75 & 8384 & 8201 & 2.20 \\
\hline 7 & 24 & 0.31 & 0.32 & -1.89 & 12 & 537 & 600 & -11.1 \\
\hline 8 & 1.25 & 18.4 & 18.3 & 0.36 & 1.5 & 11040 & 11100 & -0.54 \\
\hline 8 & 10 & 0.33 & 0.34 & -2.70 & 24 & 425 & 466 & -9.08 \\
\hline 9 & 0.83 & 11.4 & 11.3 & 0.82 & 1.25 & 12290 & 12198 & 0.75 \\
\hline 9 & 5 & 0.31 & 0.30 & 1.99 & 20 & 318 & 300 & 5.66 \\
\hline 10 & 1.25 & 16.3 & 17.0 & -4.36 & 1.25 & 7839 & 7854 & -0.20 \\
\hline 10 & 10 & 0.38 & 0.37 & 4.81 & 16 & 334 & 332 & 0.65 \\
\hline
\end{tabular}

${ }^{\text {a }}$ Expressed as [(initial conc. - re-assay conc. $) /$ average $] \times 100 \%$.

than 0.9952 for MP and 0.9932 for MPA during the entire course of validation.

Intra-day precision and accuracy results were calculate using two different batches analyzed on a single day, whereas inter-day results were calculated using five different batches analyzed on a three successive day. The acceptable intra-day and inter day precision and accuracy results of MP and MPA are presented in Table 2.

\section{Extrication efficiency and dilution integrity}

SPE procedure gave good and reproducible recoveries for the analytes. The relative recoveries of MP at LQC, MQC and HQC levels were $83.0 \%$, $82.5 \%$ and $90.9 \%$, respectively with the precision range of $2.20-7.66 \%$. Similarly, the relative recoveries of MPA at LQC, MQC and HQC levels were $89.9 \%, 93.7 \%$ and $91.0 \%$, respectively with the precision range of $1.94-9.55 \%$. The recovery (with the precision range) of the IS1 and IS2 were $89.4 \%$ (4.34-8.01\%) and $95.0 \%$ (7.17-8.19\%), respectively.

The upper concentration limit of MP and MPA can be extended to 31.7 $\mathrm{ng} / \mathrm{mL}$ and $31961 \mathrm{ng} / \mathrm{mL}$ (1.6 times of ULOQ), respectively by using half (1:2) or quarter (1:4) dilution with screened human blank plasma. The result of dilution integrity was deemed acceptable for 2 times and 4 times dilutions.

\section{Reinjection reproducibility and run size evaluation}

Re-injection reproducibility experiment was executed to check whether the instrument performance after rectification of any instrument failure during real subject sample analysis. The results demonstrate that the reinjected samples were stable for 37 hours. The percent stability of MP ranged from $94.3 \%$ to $104 \%$ with the precision range of $3.62 \%$ to $3.46 \%$. Similarly, the percent stability of MPA ranged from $98.0 \%$ to $102 \%$ with the precision range of $2.08 \%$ to $4.39 \%$.

A batch size of 195 samples containing 40 sets each of LQC, MQC1, MQC2 and HQC (samples stored at $-70^{\circ} \mathrm{C}$ ) and 24 freshly spikes QC samples (6 sets at each level) were analyzed for the long run evaluation. The results obtained for run size evaluation experiment were well within the acceptable limits (data not presented).

\section{Stability studies}

Stock solution stability was performed to check stability of MP, MPA, IS1 and IS2 in stock solutions prepared in methanol and stored in refrigerator at $2-8^{\circ} \mathrm{C}$. All the stock solutions were stable for 23 days. The percentage stability of MP, MPA, IS1 and IS2 was 103\%, 99.5\%, 99.5\% and $98.1 \%$, respectively.

All the stability tests for MP and MPA were studied at LQC and HQC levels. It was confirmed that the spiked plasma samples were stable after 4 repeated freeze and thaw cycles. Also, the results revealed that MP and MPA were stable in plasma for $9 \mathrm{~h}$ at room temperature, $54 \mathrm{~h}$ in autosampler $\left(10^{\circ} \mathrm{C}\right)$ and $51 \mathrm{~h}$ of in refrigerator (wet extract stability). The long-term stability of plasma samples stored at $-70{ }^{\circ} \mathrm{C}$ were evaluated and the results indicated that MP and MPA was stable in plasma up to 80 days. All the stability study results were well within the specified limits over the total validation (Table 3). Whole blood stability data for MP and MPA were found acceptable and are presented in Table 4. 

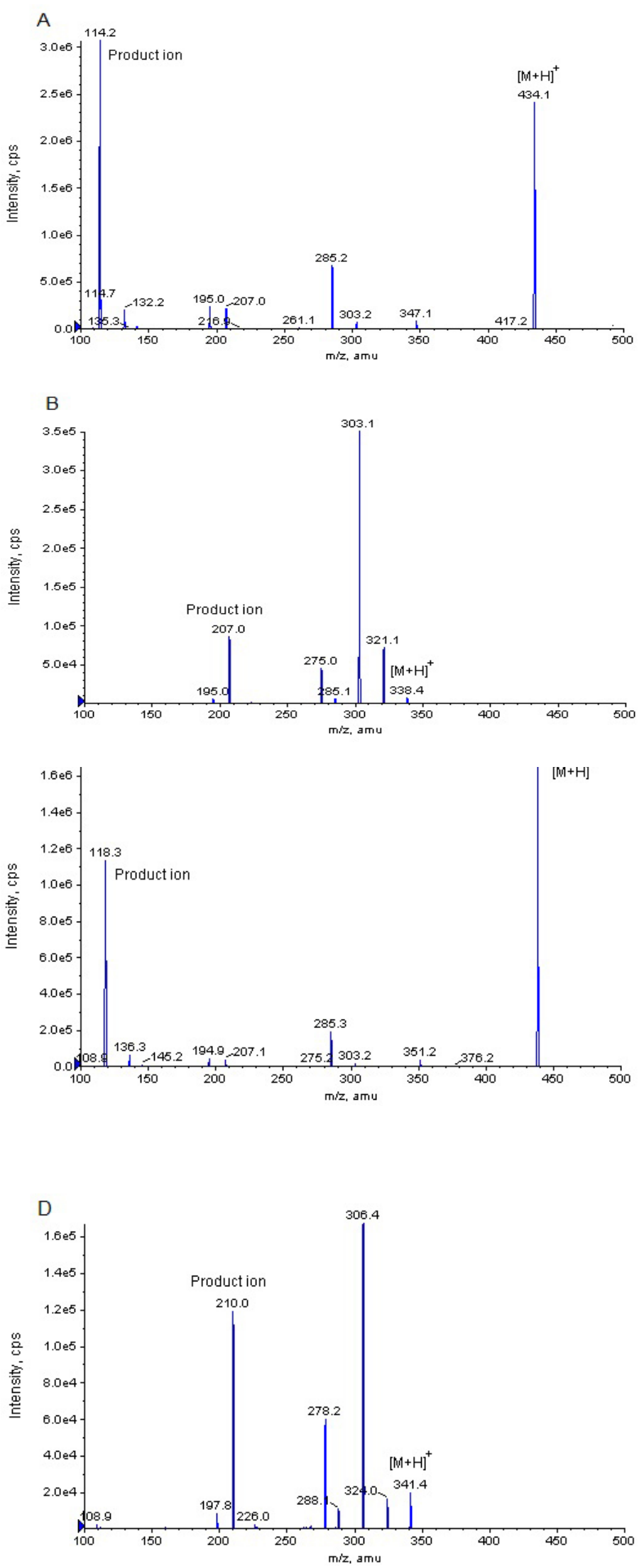

Figure 1: Product ion mass spectra of $[\mathrm{M}+\mathrm{H}]+$ of $(\mathrm{A})$ mycophenolate mofetil, (B) mycophenolic acid, (C) mycophenolate mofetil d4 (IS1) and (D) mycophenolic acid d3 (IS2).

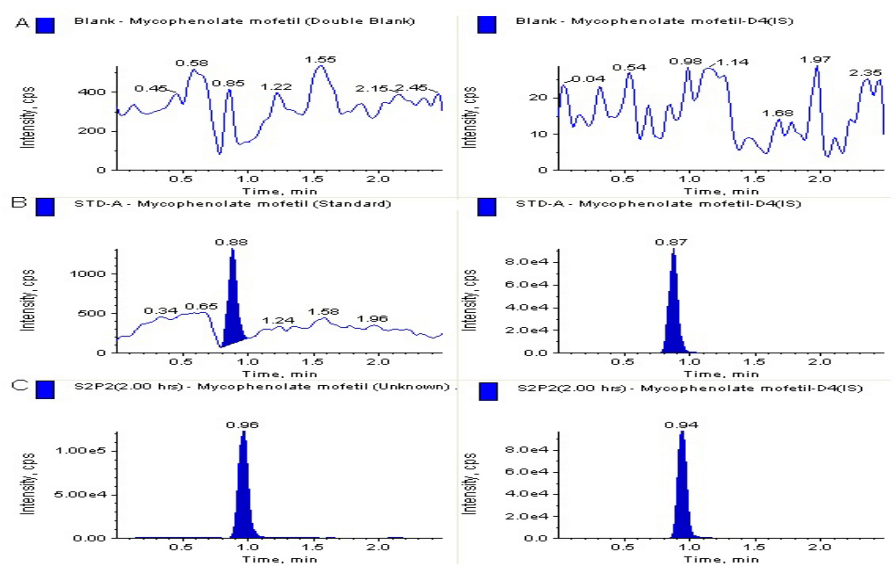

Figure 2: Typical MRM chromatograms of mycophenolate mofetil (left panel) and the IS (right panel) in human blank plasma (A), a LLOQ sample along with IS (C), and a $2 \mathrm{~h}$ subject plasma sample (12.6 ng/mL).
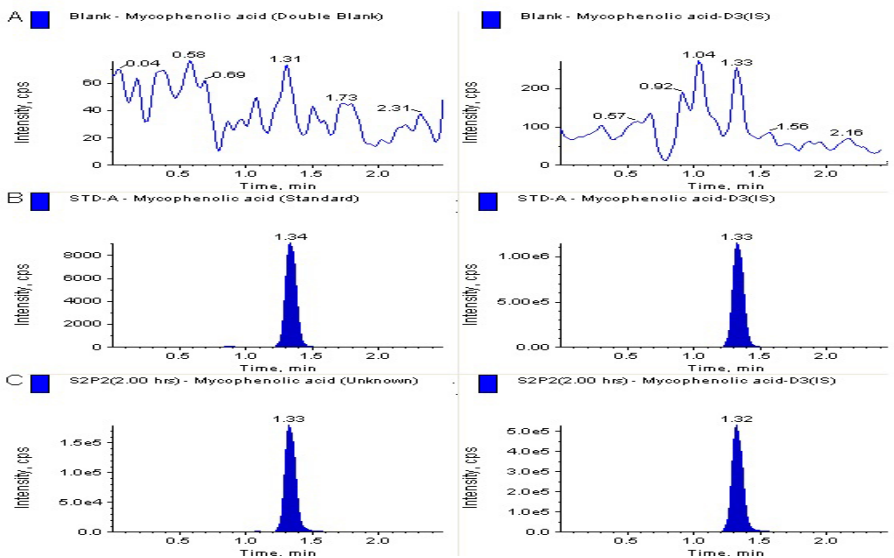

Figure 3: Typical MRM chromatograms of mycophenolic acid (left panel) and the IS (right panel) in human blank plasma (A), a LLOQ sample along with IS (C), and a $2 \mathrm{~h}$ subject plasma sample $(2200 \mathrm{ng} / \mathrm{mL})$.

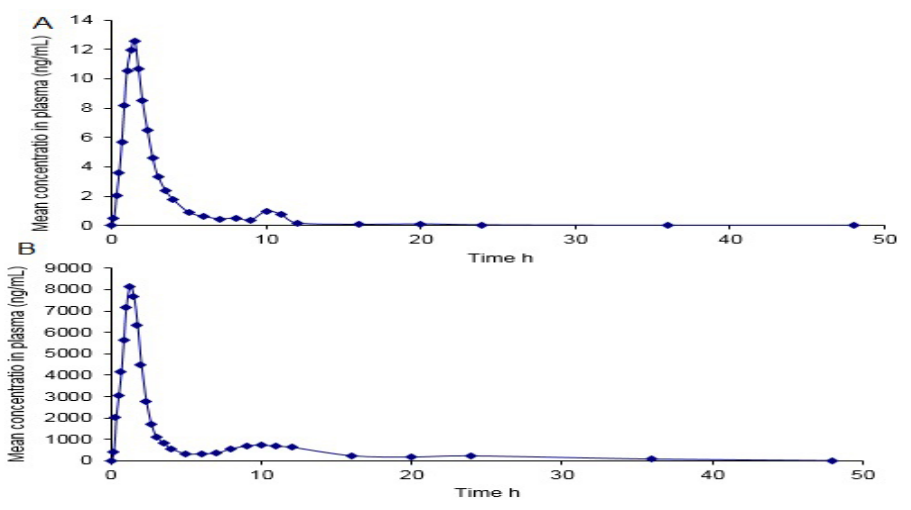

Figure 4: Mean plasma concentration-time profile of mycophenolate mofetil (A) and mycophenolic acid (B), in human plasma following oral dosing of 500 mg mycophenolate mofetil tablet to healthy volunteers $(n=10)$.

\section{Application of the proposed method}

The developed LC-MS/MS method was applied to the pharmacokinetic study of mycophenolate mofetil in healthy human subjects. Ten healthy volunteers aged 20-40 years and body-mass index (BMI) of $\geq 18.5 \mathrm{~kg} / \mathrm{m}^{2}$ and $\leq 24.9 \mathrm{~kg} / \mathrm{m}^{2}$, with body weight not less than $50 \mathrm{~kg}$ were selected for 
the study. After an overnight fast ( $12 \mathrm{~h}$ ), each volunteer was given single dose of $500 \mathrm{mg}$ mycophenolate mofetil tablet with $200 \mathrm{~mL}$ of water. No food was allowed until $3 \mathrm{~h}$ after oral administration of the doses. About $4 \mathrm{~mL}$ of blood samples were collected from the forehand vein into $\mathrm{K}_{2}$ EDTA vacutainer collection tubes before $(0 \mathrm{~h})$ and at $0.167,0.33,0.5$, $0.67,0.83,1,1.25,1.5,1.75,2,2.33,2.67,3,3.5,4,5,6,7,8,9,10,11,12$, $16,20,24,36$ and $48 \mathrm{~h}$ after dosing. Plasma was separated by centrifugation at $3200 \mathrm{rpm}$ for $10 \mathrm{~min}$ and kept frozen at $-70 \pm 10^{\circ} \mathrm{C}$ until analysis. The pharmacokinetic parameters were calculated by using Phoenix WinNonlin software (Version 6.4). Non-compartmental model was used to calculate the pharmacokinetics parameters. The plasma concentration time profiles of MP and MPA are illustrated in Figure 4 and the estimated pharmacokinetic parameters are listed in Table 5.

Now a days, regulatory agencies ${ }^{20,21}$ are insisted to perform the incurred sample reanalysis (ISR) for bioavailability and bioequivalence studies to authenticate the study data. A total of 20 samples (near to Cmax and the elimination phase) for each analyte were evaluated for ISR. These results furthermore supported our improved method techniques and reproducibility of the study data as well. The ISR data are further presented in Table 6.

\section{CONCLUSIONS}

In conclusion, a simple, rapid, specific and high-throughput LC-MS/ MS method has been developed and validated to quantify MP and MPA in human plasma. The method utilizes deuterated standards as internal standards for quantification. To the best of knowledge, this is the first LC-MS/MS report describes the complete method development and validation procedure for the simultaneous quantification of MP and MPA in human plasma suitable for pharmacokinetic or bioavailability/ bioequivalence application. The selectivity of method in hemolyzed and lipemic plasma and stability of MP and MPA in plasma are unique features of the method. Overall the proposed method showed excellent selectivity, adequate sensitivity, controlled matrix effect and good reproducibility for the determination of MP and MPA in human plasma. A sample run time of $2.5 \mathrm{~min}$, allowing the quantification of more than 350 samples in a day. This method has been fully validated as per the requirement of global regulatory agencies like US FDA and EMEA. The method showed suitability for clinical studies in humans. Furthermore, the ISR at the end of the study added strength to our existing method. All the advantages would make our method efficient for bioavailability and bioequivalence (BA/BE) studies and routine therapeutic drug monitoring with the desired precision and accuracy.

\section{CONFLICT OF INTEREST}

The authors declare no conflict of interest.

\section{ABBREVIATIONS}

LC-MS/MS: Liquid Chromatography/Tandem Mass Spectrometry; MRM: Multiple Reaction-Monitoring Mode; US FDA: United States Food and Drug Administration; HPLC: High Performance Liquid Chromatography; IS: Internal Standard; SPE: Solid-Phase Extraction; DP: Declustering Potential; CE: Collision Energy; EP: Entrance Potential; CXP: Collision Cell Exit Potential; LLOQ QC: Lower Limit of Quantitation Quality Control; LQC: Low Quality Control; MQC: Medium Quality Control; HQC: High Quality Control; EDTA: Ethylenediaminetetraacetic acid; ER: Extended Release; ISR: Incurred Sample Reanalysis; ESI: Electro Spray Ionisation; ULOQ: Upper Limit of Quantitation.

\section{Highlights of Paper}

- First LC-MS/MS report for the simultaneous determination of mycophenolate and mycophenolic acid in human plasma.

- Isotope labeled compound used as an internal standards to get better precision and accuracy.

- Fully validated as per the current US FDA and EMEA guidelines.

- The method employs only $100 \mu \mathrm{L}$ of plasma volume and achieved acceptable sensitivity.

- The total analysis time is shortest compared to all existing methods.

- Method reproducibility was demonstrated by incurred sample reanalysis.

\section{REFERENCES}

1. Krejci M, Doubek M, BuchlerT, Brychtova Y, Vorlicek J, Mayer J. Mycophenolate mofetil (MPM) for the treatment of acute and chronic steriod-refractory graftversus-host disease. Ann Hematol. 2005;84:681-5.

2. Ransom JT. Mechanism of action of mycophenolate mofetil. Ther Drug Monit. 1995; 17:681-4.

3. Nowak I, Shaw LM. Mycophenolic acid binding to human serum albumin: characterization and relation to pharmacodynamics. Clin Chem. 1995;41(7):1011-7.

4. Barzoki MA, Rouini M, Gholami K, Lessan-Pezeshki M, Rezaee S. Determination of mycophenolic acid in human plasma by high-performance liquid chromatography. DARU. 2005;13(3):120-6.

5. Gao JW, Peng ZH, Li XY, Sun B, Guo YK, Liu GL. Simultaneous determination of mycophenolic acid and its metabolites by HPLC and pharmacokinetic studies in rat plasma and bile. Arch Pharm Res. 2011;34(1):59-69.

6. Shipkova M, Niedmann PD, Armstrong WW, Schütz E, Wieland E, Shaw LM, et al. Simultaneous determination of mycophenolic acid and its glucuronide in human plasma using a simple high-performance liquid chromatography procedure. Clin Chem. 1998;44(7):1481-8.

7. Kawanishi M, Yano I, Yoshimura K, Yamamoto T, Hashi S, Masuda S, et al. Sensitive and validated LC-MS/MS methods to evaluate mycophenolic acid pharmacokinetics and pharmacodynamics in hematopoietic stem cell transplant patients. Biomed Chromatogr. 2015;29(9):1309-16.

8. Md Dom ZI, Noll BD, Coller JK, Somogyi AA, Russ GR, Hesselink DA, et al. Validation of an LC-MS/MS method for the quantification of mycophenolic acid in human kidney transplant biopsies. J Chromatogr B Analyt Technol Biomed Life Sci. 2014;945-6:171-7.

9. Wiesen MH, Farowski F, Feldkötter M, Hoppe B, Müller C. Liquid chromatographytandem mass spectrometry method for the quantification of mycophenolic acid and its phenolic glucuronide in saliva and plasma using a standardized saliva collection device. J Chromatogr A. 2012;1241:52-9.

10. Buchwald A, Winkler K, Epting T. Validation of an LC-MS/MS method to determine five immunosuppressants with deuterated internal standards including MPA. BMC Clin Pharmacol. 2012;12(1):2.

11. Klepacki J, Klawitter J, Bendrick-Peart J, Schniedewind B, Heischmann S, et al. A high-throughput U-HPLC-MS/MS assay for the quantification of mycophenolic acid and its major metabolites mycophenolic acid glucuronide and mycophenolic acid acyl-glucuronide in human plasma and urine. J Chromatogr B Analyt Technol Biomed Life Sci. 2012;883-4:113-9.

12. Kuhn J, Götting C, Kleesiek K. Sample cleanup-free determination of mycophenolic acid and its glucuronide in serum and plasma using the novel technology of ultra-performance liquid chromatography-electrospray ionization tandem mass spectrometry. Talanta. 2010;80(5):1894-8.

13. Shen B, Li S, Zhang Y, Yuan X, Fan Y, Liu Z, et al. Determination of total, free and saliva mycophenolic acid with a LC-MS/MS method: application to pharmacokinetic study in healthy volunteers and renal transplant patients. J Pharm Biomed Anal. 2009;50(3):515-21.

14. Kuhn J, Prante C, Kleesiek K, Götting C. Measurement of mycophenolic acid and its glucuronide using a novel rapid liquid chromatography-electrospray ionization tandem mass spectrometry assay. Clin Biochem. 2009;42(1):83-90.

15. Upadhyay V, Trivedia V, Shaha G, Yadav M, Shrivastav PS. Determination of mycophenolic acid in human plasma by ultra-performance liquid chromatography tandem mass spectrometry. J Pharma Anal. 2014;4:205-16.

16. Tsina I, Kaloostian M, Lee R, Tarnowski T, Wong B. High-performance liquid chromatographic method for the determination of mycophenolate mofetil in human plasma. J Chromatogr B Biomed Appl. 1996;681(2):347-53.

17. Renner UD, Thiede C, Bornhäuser M, Ehninger G, Thiede HM. Determination of mycophenolic acid and mycophenolate mofetil by high-performance liquid chromatography using postcolumn derivatization. Anal Chem. 2001;73(1):41-6.

18. Das R, Pal TK. Validation of liquid chromatography-tandem mass spectrometry for mevalonate in human plasma: Incompetent effects between treated atorvastatin \& its combination with olmesartan in cardiovascular patients. J Young Pharm. 2015;6:50-7. 
19. Draft Guidance on Mycophenolate Mofetil, US Food and Drug Administration's (FDA's) February 2014. https://www.google.co.in/?gws_ $r d=s s \mid \# q=m y c o p h e n o l a t e+a n d+o g d$. Accessed on 20th August 2015.

20. US DHHS, FDA and CDER. Draft Guidance for Industry: Bioanalytical Method Validation. US Department of Health and Human Services, Food and Drug Administration, Center for Drug Evaluation and Research and Center for Veterinary Medicine, 2013. Available at: http://www.fda.gov/downloads/drugs/ guidancecomplianceregulatoryinformation/guidances/ucm368107.pdf.
21. Guideline on bioanalytical method validation, Science and Medicinal Health, European Medicines Agency (EMEA), EMEA/CHMP/EWP/192217/2009; 21 July 2011.

22. Raghunadha RS, Sarath $\mathrm{Cl}$, Jayaveera KN, Koteswara Rao D. Quantification of ibuprofen in human plasma by using high throughput liquid chromatographytandem mass spectrometric method and its applications in pharmacokinetics. Arc Appl Sci Res. 2010;2(3):101-11

Article History: Submission Date: 26-08-15; Revision Date: 11-09-15; Accepted Date: 21-09-15.

Cite this article: Maddela R, Pilli NR, Maddela S, Pulipati CR, Polagani SR, Makula A. A novel and Rapid LC-MS/MS assay for the Determination of Mycophenolate and Mycophenolic Acid in Human Plasma. J Young Pharm. 2017;9(1):106-13. 